\title{
O esporte e o ensino médio: a visão dos professores de educação física da rede pública
}

CDD. 20.ed. 373

796.017
Marco Aurélio Gonçalves Nóbrega dos SANTOS*

Vilma Lení NISTA-PICCOLO*
*Universidade São Ju-

das Tadeu.

\begin{abstract}
Resumo
0 presente trabalho investigou a visão que o professor de Educação Física, que atua no Ensino Médio, tem sobre a aplicação do esporte em suas aulas na escola. Buscamos identificar qual a concepção atribuída ao esporte e à competição, bem como verificar qual o sentido da prática esportiva nesse contexto. Numa pesquisa do tipo qualitativa foram coletadas informações a partir de uma ficha diagnóstica das escolas, além de uma entrevista semiestruturada com esses profissionais. Uma pergunta geradora norteava a investigação: Como você vê a relação Esporte/Educação Física? As respostas obtidas foram interpretadas por meio da técnica de análise de conteúdo, BARDIN (2004). 0 estudo consta de duas etapas, na primeira está uma revisão bibliográfica sobre as questões que permeiam a prática esportiva na Educação Física escolar no Ensino Médio e, na segunda, o desenvolvimento metodológico dessa pesquisa. Os resultados apresentados apontam o esporte relacionado aos seguintes temas: esporte e educação, que declara uma falta de compromisso por parte dos docentes; esporte e saúde, que se configura com equívocos conceituais; esporte e competição, que demonstra uma ênfase na prática seletiva; esporte como um aspecto cultural, visto como fundamental na contribuição à cultura da sociedade; esporte na perspectiva das modalidades tradicionais, definido como únicas perspectivas de prática pedagógica, esporte e inclusão, que revela a predominância das atividades exclusivas aos mais hábeis.
\end{abstract}

UnIteRmos: Educação física escolar; Pedagogia do esporte; Ensino médio.

\section{Introdução}

No debate educacional, uma das preocupaçōes dos professores de Educação Física centra-se na discussão do papel assumido pela Educação Física nas escolas, com a tarefa de traçar um mapa geral dos problemas ali existentes.

O professor, em sua prática pedagógica, pode propiciar elementos que favoreçam a formação desses jovens como agentes transformadores. Mas é necessário, também, que o professor identifique os instrumentos de ação pedagógica a serem usados em suas aulas de Educação Física, estimulando a auto-motivação dos seus alunos, tornando-os mais criativos em busca de seu desenvolvimento.

No decorrer dos anos a sociedade construiu uma visão sobre a Educação Física que entende que o espaço e o tempo escolar estejam vinculados ao fenômeno esportivo, ou seja, o esporte é o conteúdo central tratado nas aulas pelos professores, é a prática corporal citada e valorizada pelos alunos, é a referência para as atividades extracurriculares da Educação Física. A compreensão do que significa ensinar/aprender esporte não é tão simples, apesar da ideia, muito comum, de que ensinar um esporte é ensinar a praticá-lo. Conhecer o esporte não significa apenas saber executá-lo, mas também saber suas regras, sua história, sua inserção sociopolítica. Esse aspecto possibilita a realização de uma proposta pedagógica da Educação Física, que apresenta uma prática esportiva fundamentada numa visão crítica do fenômeno esporte.

Ciente de que todo profissional de Educação Física necessita de uma base teórica para orientar sua prática pedagógica, faz-se necessário repensar o esporte no contexto escolar, considerando-o como conteúdo de uma disciplina comprometida com o processo educativo. Deve-se ficar atento para o modelo de esporte a partir do qual o profissional de 
Educação Física desenvolve suas aulas, pois na escola existe a prática esportiva extraescolar, relacionada aos modelos de performance, visando ao rendimento e permitindo a comparação objetiva de resultados.

A escola é, acima de tudo, o local instituído para a ação educativa formal e que se dá mediante o processo político pedagógico. Por isso, a atuação do professor de Educação Física deve fazer com que, por meio de seus conteúdos, propiciem aos alunos compreenderem as diversas formas de manifestaçôes esportivas. A intenção não é ensinar a praticar determinadas modalidades esportivas e conhecer apenas suas formas, suas aplicações e organizações, mas o papel é fazer com que adquiram autonomia para a prática dessas modalidades esportivas com um senso de reflexão crítica sobre como, quando, onde e para

\section{Caminhos metodológicos}

Nossa pesquisa se deu nas escolas que possuem Ensino Médio no município de Ourinhos (SP), totalizando oito escolas e 10 professores de Educação Física, os quais concordaram em participar do estudo.

Convém ressaltar que os critérios de inclusão dos participantes na pesquisa foram: a atuação no Ensino Médio em escolas públicas do município de Ourinhos e o aceite do professor em participar espontaneamente desse estudo a partir da assinatura do Termo de Consentimento Livre e Esclarecido e segundo as normas e aprovação do Comitê de Ética em Pesquisa da Universidade São Judas Tadeu.

No sentido de atingirmos o objetivo referente a melhor compreensão das percepções e concepções dos participantes sobre a relação Esporte/Educação Física e seus significados elegemos como instrumentos da coleta de dados a entrevista semiestruturada, associada a uma ficha diagnóstica, elaborada junto à Diretoria Regional de Ourinhos (DERO). Essa ficha nos revelou as seguintes informações: qual a sua situação funcional (concursados, estáveis, contrato

\section{Resultados e discussão}

Dos 10 professores entrevistados, sete são professores concursados, os quais são chamados de efetivos titulares de cargo; dois são estáveis, não são concursados, mas têm estabilidade por estar há mais de cinco anos atuando no ensino público; e um foi que elas se manifestam nas mais variadas situações, nesse caso, no cenário escolar.

A questão que norteou a problemática desse trabalho foi: Qual o entendimento, a visão, a perspectiva que o profissional que desenvolve essa prática esportiva no ambiente escolar tem sobre este fenômeno cultural?

Partindo então do tema a ser investigado - o esporte na escola - surge a seguinte problemática:

Qual é a relação Esporte/Educação Física na visão dos professores de Educação Física do Ensino Médio das escolas do município de Ourinhos (SP)?

$\mathrm{Na}$ busca de respostas ao problema proposto, estabeleceu-se o seguinte objetivo: investigar a visão dos professores de Educação Física do ensino médio sobre o fenômeno Esporte e sua relação com a Educação Física.

temporário e substituto); a formação acadêmica do professor; tempo de atuação no Ensino Médio; a participação em outras atividades profissionais. Apresenta ainda as condições de infraestrutura das escolas para as aulas de Educação Física, ou seja, quadras, materiais, iluminação e conservação.

A principal fonte de dados usada para a análise e interpretação foram as entrevistas, as quais, numa abordagem qualitativa, foram tratadas na técnica de análise de conteúdo, modalidade temática, proposta por BARDIN (2004). O motivo da escolha de tal técnica se justifica por ser um instrumento que, com maior rigor, analisa o vasto campo das comunicações, facilitando a tentativa exploratória e enriquecendo as interpretações.

Para BARdin (2004):

A análise de conteúdo é um conjunto de técnicas visando obter, por procedimentos, sistemáticos e objetivos de descrição do conteúdo das mensagens, que permitam inferência de conhecimentos relativos às condições de produção/recepção dessas mensagens (p.42).

admitido por contrato temporário, chamado de ACT (Admissão em Caráter Temporário). No que se refere à formação acadêmica desses professores, identificamos que oito deles são formados em instituiçōes públicas e dois em instituição particular. 
Quanto ao tempo de formação acadêmica, observamos que cinco desses professores já atuam há mais de 10 anos no ensino público estadual, três estão entre seis e 10 anos de atuação, um atua de dois a cinco anos e um está no ensino público há apenas um ano. No aspecto da atuação desses profissionais nas escolas observou-se que oito estão formados entre seis e 10 anos, destes, verificamos que cinco deles só atuam no ensino público e não têm nenhum outro tipo de atividade profissional; três além de atuarem no ensino público estadual, também atuam na rede municipal e dois têm atividades profissionais em outros segmentos, ou seja, fora do ensino e fora da área da Educação Física.

Em relação aos materiais esportivos, identificamos que quatro professores $(2,5,6$ e 9$)$ declararam ter pouco material esportivo, apontando bolas, entre outros materiais. Os professores 2 e o 6 têm apenas uma bola de futsal, já o professor 7 tem duas bolas e os professores 8 e 10 podemos considerar que têm um pouco de material, mas não o suficiente, ou seja, quatro e sete bolas, respectivamente. Foi possível identificar que apenas três professores $(1,8$ e 10$)$ têm uma quantidade de bolas considerada suficiente em todas as modalidades, apresentando uma média acima dos outros materiais. Já nos itens apontados como estruturas que ficam expostas ao ambiente, como as quadras, tabelas, aros, postes e traves, percebemos que, na sua maioria, estão classificadas como boas e regulares. Quanto às quadras cobertas, duas foram classificadas como muito boas, cinco como boas, uma regular e duas fracas. No que diz respeito à iluminação e à conservação delas, os professores declaram o seguinte: quatro são boas, quatro são regulares e duas são apontadas como classificação fraca.

Com essa análise e interpretação foi possível ter uma visão bem próxima e bastante real de como as escolas em que os professores entrevistados estão inseridos apresentam-se em relação às estruturas físicas e materiais, bem como, quais são os perfis de formação e atuação. Assim, podemos observar melhores pontos significativos para uma prática rica em relação ao seu ambiente.

Com a entrevista, buscamos descobrir o que pensa o professor entrevistado, sobre o esporte como uma possibilidade de conteúdo da Educação Física escolar.
A questão que norteou essa investigação foi elaborada previamente com a intenção de oportunizar a expressão livre, mas orientada, dos professores entrevistados e, por meio delas, analisar suas visōes. A questão foi:

Como você vê a relação Esporte/Educação Física?

As entrevistas foram organizadas de forma a ordená-las em redução de dados obtidos, ou seja, a partir dos discursos dos professores entrevistados foram construídas as Unidades de Registro (UR), aspectos levantados pelo pesquisador, nas quais foram agrupadas e construídas as Unidades de Contexto, gerando temas principais a serem interpretados. Assim os temas das unidades foram: esporte e educação; esporte e saúde; esporte e competição; o esporte como aspecto cultural; esporte na perspectiva das modalidades tradicionais; esporte e inclusão.

A construção das Unidades de Contexto e, consequentemente, dos temas acima elencados foram construídos a partir dos discursos dos professores, por intermédio de sucessivas leituras das entrevistas, buscando se estabelecer dois objetivos muito claros. O primeiro: criar uma sequência lógica entre os assuntos, permitindo assim um aprofundamento maior nas reflexões; o segundo: criar um ambiente, uma oportunidade para o entrevistado relatar seu ponto de vista, falando espontaneamente sobre o tema, apontando, assim, as situações de relação entre o esporte e à educação física no Ensino Médio dentro de perspectivas da atual realidade em que se encontram inseridos no contexto escolar.

Ao propor um trabalho que discutisse a relação do esporte nas aulas de Educação Física no Ensino Médio, procuramos mostrar a realidade desse quadro na escola pública e, principalmente, como pensa o professor que está inserido nesse contexto sobre esse tema, permitindo que ele apresentasse o significado e o sentido de suas ações pedagógicas.

Segundo os objetivos tratados nesse estudo, buscamos identificar como o esporte tem sido tratado pelos professores de Educação Física no Ensino Médio e, para isso, os dados apresentados foram contextualizados em temáticas que pudessem melhor esclarecer a relação estabelecida a respeito do esporte como prática de Educação Física. 


\section{A educação física escolar e o ensino médio}

Antes da reforma curricular do Ensino Médio, a política educacional priorizava a formação de especialistas para esse nível de ensino. As mudanças nesse sentido ocorreram face à busca de um ensino preparatório para o ingresso na Universidade.

"A reformulação do ensino médio no Brasil... procurou atender a uma reconhecida necessidade de atualização da educação brasileira" (BRASIL, 2002, p.7), em função de enfrentar os desafios impostos por processos globais, para uma parcela de jovens que completam a educação básica, os quais, de certa forma, se sentiam excluídos da vida econômica como trabalhadores não qualificados.

Há, a partir da década de 80 , uma nítida expansão do Ensino Médio no Brasil em termos do seu crescimento. É a fase do rompimento com os velhos paradigmas educacionais com seus currículos estritamente disciplinares.

Com isso, a Lei de Diretrizes e Bases da Educação Nacional (Lei 9.394/96) confere uma nova identidade ao Ensino Médio, determinando que o Ensino Médio faça parte da educação básica. Isso significa dizer que o Ensino Médio passa a integrar a etapa do processo educacional que a nação considera básico para o exercício da cidadania, ou seja, como base para o acesso às atividades produtivas, para o prosseguimento nos níveis mais elevados e complexos de educação e para o desenvolvimento pessoal referido à sua interação com a sociedade e sua plena inserção nela.

A Lei n. 9.394/96 declara que o Ensino Médio "tem por finalidades desenvolver o educando, assegurar-lhe a formação comum indispensável para o exercício da cidadania e fornecer-lhe meios para progredir no trabalho e em estudos posteriores" (Art. 22). Essas mudanças vieram juntas com outros documentos, as Diretrizes Curriculares Nacionais - DCN (BRAsIL, 1999) e os Parâmetros Curriculares Nacionais - PCN (BRASIL, 2002) criando um novo Ensino Médio integrando a chamada formação básica, cujos principais objetivos são preparar o indivíduo para o vestibular e para o mercado de trabalho, não mais o profissionalizando, mas sim fazendo com que se ajuste a ele (BRASIL, 2002). Porém, há de se ressaltar que os $\mathrm{PCN}$ s chegaram às escolas, mas provocar mudanças, como era esperado, não, pois o que se percebe é que os documentos são superficiais junto aos professores o que consequentemente pouco auxilia nas ações didático-pedagógicas, pois é extremamente necessário que haja espaço para discussões, debates, opiniōes, juntamente com processo de construção dessas açōes, não que esse espaço não exista, até existe, no entanto, quando isso acontece, a presença dos professores de Educação Física é muito tímida e isso se torna mais crítico, pois o professor acaba sabendo de fato qual o papel do seu componente curricular frente aos objetivos do Ensino Médio.

De acordo com as novas proposiçóes para a Educação Física no Ensino Médio, ou seja, sua inserção na área de Linguagens, Códigos e suas Tecnologias, surge uma enorme gama de diferentes formas de atuação do professor visando a variedades de aprendizagens a serem conquistadas. De certo modo, isso provoca um rompimento com o que frequentemente se vê no cenário atual, no qual aparece uma repetição do que acontece no Ensino Fundamental, voltada, quase que na sua totalidade, às práticas das modalidades esportivas, em geral desenvolvidas por meio de competições. No sentido de contribuir para a formação dos alunos tem que se mostrar e expressar as novas maneiras desse conteúdo.

Para que de fato o desenvolvimento das competências e habilidades propostas nos Parâmetros Curriculares Nacionais (BrASIL, 2002) aconteça juntamente com os objetivos do Ensino Médio é preciso transpor barreiras, quebrar paradigmas, até mesmo confrontar com a própria escola e fazer com que o professor compreenda e acredite que a Educação Física, enquanto componente curricular, tem um fim em si mesmo levando a encontrar novos paradigmas como o planejamento participativo e a interdisciplinaridade.

\section{Esporte e educação}

Sobre a temática "Esporte e Educação", ficou claro a falta de compreensão dos professores em relacionar a política educacional com a proposta pedagógica, justificando ser essa a maior dificuldade em tratar o tema como conteúdo das aulas de Educação Física, apresentando muita resistência para novas mudanças conforme os relatos dos entrevistados: 


\begin{tabular}{|c|c|}
\hline UR - 01 & 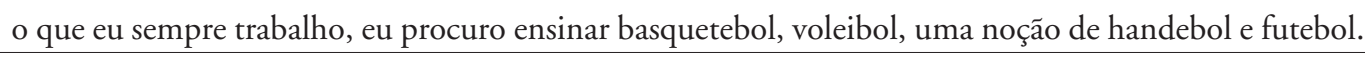 \\
\hline UR - 06 & $\begin{array}{l}\text { então eu uso como base os desportos que eles estão acostumados entre aspas a tentar praticar que são: } \\
\text { futsal, vôlei, handebol e basquete. }\end{array}$ \\
\hline UR - 07 & $\begin{array}{l}\text { Há condições de você trabalhar com outros esportes, porém, você tem que fazer uma adaptação, um jogo } \\
\text { de cintura, você tem que negociar, realmente hoje você negocia com o aluno pra ele fazer ou não sua aula. }\end{array}$ \\
\hline UR - 08 & $\begin{array}{l}\text { então eu tento aprofundar o esporte que eles praticam, que eles gostam, mostrando os outros segmentos } \\
\text { que são atrelados a ele. }\end{array}$ \\
\hline UR - 09 & $\begin{array}{l}\text { a política educacional não prevê esporte na escola, então eles querem esporte em qualquer lugar, menos } \\
\text { na escola. }\end{array}$ \\
\hline UR - 10 & $\begin{array}{l}\text { O nosso sistema educacional, ele é baseado no sistema americano...é...onde lá o esporte funciona por } \\
\text { temporada tá...isso de uma maneira competitiva, a partir do segundo grau. }\end{array}$ \\
\hline UR - 29 & Os conteúdos que eu trabalho do esporte basicamente é...os fundamentos dos esportes. \\
\hline UR - 46 & $\begin{array}{l}\text { então os esportes que eu estou fazendo é basquete né, que é dividido em quatro bimestres: basquete, } \\
\text { handebol, vôlei e futsal. }\end{array}$ \\
\hline UR - 47 & 1 \\
\hline
\end{tabular}

Assim, percebemos que o esporte continua sendo tratado de modo seletivo e reducionista. O sistema educacional é o alvo das críticas pela situação em que se encontram atualmente os professores. Mas, a dificuldade em aceitar que é preciso enfrentar novos desafios, mostrar maior interação da teoria com a prática, e rever as práticas pedagógicas têm impedido a evolução das aulas de Educação Física na escola. Faltam reflexões que tornem as práticas profissionais mais efetivas no âmbito escolar. Faltam compromisso e interesse por parte dos professores em buscarem novas perspectivas de sua atuação, formas diferentes de tratar o esporte, contribuindo com o aspecto educacional dos alunos. Assim, destacamos que não existe um entendimento do significado do esporte como um fenômeno sociocultural, trabalhado como um dos conteúdos de um processo de ensino-aprendizagem nas aulas de Educação Física, por parte desses professores.

As aulas de Educação Física no Ensino Médio costumam repetir os programas do Ensino Fundamental, resumindo-se às práticas dos fundamentos de algumas modalidades esportivas e à execução dos gestos técnicos esportivos. É como se a Educação Física se restringisse a isso. Não se trata, evidentemente, de desprezar tais práticas no contexto escolar, mas sim de ressignificá-las

Kunz (1995) aponta que um dos fatos do professor agir sem preocupação com o caráter pedagógico em sua prática se deve ao fato de que durante sua formação não lhe foi proporcionado análises e reflexôes sobre os conhecimentos adquiridos, o que reflete um saber predominantemente instrumental, restringindo a seleção e aplicação da prática pedagógica.

Os projetos que trazem as diversas reformas educacionais preservam de forma hegemônica, excluindo os professores de tais mudanças e os reduz a um grupo de técnicos do governo e outros segmentos face às mudanças sociais. Em decorrência disso, aparecem os professores excluídos dos processos de elaboração e implementação de tais reformas e colocados na posição de executores e aplicadores. Dessa forma, esses professores buscam na formação que tiveram apenas uma atualização de conhecimentos que os possibilitem atuar com competência, porém, sem que percebam que não há evolução em relação à teoria e à prática pedagógica (Freitas, 1995; Molina Neto \& Cordero, 1996).

Assim, o que podemos perceber são problemas relativos à implantação de políticas educacionais que se mostram desalinhadas com as diferentes realidades, com propostas de flexibilização do ensino e que não consideram a formação, muitas vezes, técnicas. Entendemos que isso se refere também à Educação Física e que atualmente ainda busca sentido e significado para suas práticas.

MÉRIDA (1995, p.61), falando sobre política educacional e trabalho pedagógico, conclui que "os caminhos de uma educação pública popular passam, necessariamente, pela vontade de mudar, pela consciência dos valores defendidos e pela relação de coerência entre o discurso e a prática”.

É grande a complexidade dos problemas que permeiam a prática escolar impossibilitando que a proposta a ser trabalhada seja executada com êxito. Quando um professor tenta melhorar suas aulas, provavelmente vai se deparar com algum obstáculo que atrapalhe sua caminhada. Muitas vezes não podemos atribuir a culpa exclusivamente ao professor, pois há todo um conjunto de fatores que contribuem para o desencadeamento das atividades. 
Percebemos, então, o grande esforço da Educação Física como disciplina acadêmica para sustentar sua prática pedagógica. Entretanto, na escola, esses saberes, muitas vezes, não chegam, ou se chegam, acabam não sendo colocados em prática, ocasionando o que já está em evidência pelo senso comum, ou seja, sem a mínima reflexão sobre os valores que deverão ser transmitidos aos alunos no trabalho pedagógico.

Também podemos observar que uma grande ferramenta de auxílio ao professor de Educação
Física no Ensino Médio é o planejamento participativo, bem como a interdisciplinaridade, mas, infelizmente, não é bem comum essa ação na sua prática. Correia (1996) defende a ideia de que o Ensino Médio deve partir de um planejamento participativo, considerando algumas vantagens, como a participação dos próprios alunos e suas motivações nas atividades, a própria valorização da Educação Física e o envolvimento de outros alunos na forma de participar na elaboração da proposta.

\section{Esporte e saúde}

Sobre o tema "Esporte e Saúde" na visão dos professores, ficou evidente que essa relação se manifesta apenas na compreensão de que a saúde se dá pela prática esportiva vivenciada nas aulas de Educação Física, isto é, a saúde é concebida no seu aspecto anátomo-fisiológico. É consequência de uma prática adquirida por meio do esporte, como um fator condicionante da obtenção, manutenção e promoção dessa prática. Não há uma manifestação, por parte desses professores, dos aspectos culturais, psicológicos, econômicos e sociais da saúde, o que demonstra uma dificuldade em compreender o que ela representa e quais suas implicações dentro dos objetivos da Educação Física, quando relacionada ao esporte. Destacaram que os alunos se conscientizam da importância da saúde por meio das aplicaçōes práticas esportivas, mas, na verdade, observa-se que esse aspecto só é tratado nos discursos dos professores.

\begin{tabular}{|l|l|}
\hline UR - 05 & $\begin{array}{l}\text { a gente tenta fazer, conscientizar eles que o esporte e a atividade física vai trazer um benefício pra ele, } \\
\text { pra saúde futura e não de imediato, porque a escola não forma nenhum atleta }\end{array}$ \\
\hline UR - 12 & $\begin{array}{l}\text { prática esportiva regular é a melhor forma de você ter o desenvolvimento harmônico do corpo, tanto } \\
\text { do garoto quanto da menina. }\end{array}$ \\
\hline UR - 15 & $\begin{array}{l}\text { Ele vai saber pelo menos manter sua saúde física com o esporte saudável e não o esporte de competição } \\
\text { precoce, porque esporte de competição não significa saúde. }\end{array}$ \\
\hline UR - 17 & $\begin{array}{l}\text { A educação física deve ser trabalhada os quatro esportes e o atletismo no mínimo pra que o aluno aprenda, } \\
\text { tenha a consciência que a prática esportiva é uma atividade física saudável e a pratique durante sua vida. }\end{array}$ \\
\hline UR - 19 & $\begin{array}{l}\text { Além da prática que eu quero que seja comum a todos, assim como...como um requisito pra ele praticar } \\
\text { atividade física de lazer, pra saúde e pro prazer. }\end{array}$ \\
\hline UR - 21 & $\begin{array}{l}\text { Primeiro é que todos tenham acesso à iniciação e ao domínio dos esportes quanto uma atividade que } \\
\text { é bom pra saúde, que é lazer. }\end{array}$ \\
\hline UR - 28 & $\begin{array}{l}\text { É uma atividade física com promoção pra saúde que acredito que é uma das vertentes que eu acho im- } \\
\text { portante pra que esse pessoal saia da escola com um pouco mais de ...noção sobre...relação saúde mesmo. }\end{array}$ \\
\hline UR - 31 & $\begin{array}{l}\text { As modalidades que eu trabalho são as tradicionais porque justamente por causa do tempo, eu também } \\
\text { direcionando para área da saúde que eu gosto bastante. }\end{array}$ \\
\hline UR - 38 & $\begin{array}{l}\text { Então eu tô descobrindo ainda essa relação e eu quero tirar um pouco, um pouco não, em que as } \\
\text { pessoas olhem o esporte de uma maneira mais saudável, não tanto no aspecto competitivo. }\end{array}$ \\
\hline UR - 41 & $\begin{array}{l}\text { Aproveitei e entrei em outra área que diz respeito diretamente à saúde delas que não apenas o esporte, } \\
\text { então o esporte eu procuro fazer dessa forma. }\end{array}$ \\
\hline UR - 49 & $\begin{array}{l}\text { Eu trabalho com revistas, jornais, entrevistas sobre o esporte, a necessidade da atividade física para a } \\
\text { manutenção da saúde, a qualidade de vida. }\end{array}$ \\
\hline
\end{tabular}


No decorrer dos anos podemos verificar que as tendências didático-pedagógicas sofreram e ainda sofrem influência das correntes médica, militar e esportiva no tratamento da saúde nos programas de Educação Física escolar, demonstrando um cenário que implica as atividades físicas e esportivas como componentes para a obtenção e promoção da saúde.

Concordamos com Guedes (2004, p.127) que diz "os conceitos elaborados quanto ao que vem ser saúde devem ser objetos de cuidadosa reflexão, para que se possa perceber e atuar de forma coerente a fim de contribuir efetivamente para a melhoria da qualidade de vida das pessoas."

Por isso, entendemos que para se ter uma visão inovadora no tratamento da educação para a saúde como conteúdo da Educação Física escolar é importante que se tenha uma visão global e unificadora da saúde. Existe a necessidade de se resgatar o conceito de promoção e de educação para a saúde em dissociação de prevenção de doenças, bem como de que atividade física, aptidão física e esporte são fatores para se equacionar níveis de saúde.

Muitas vezes os professores de Educação Física estabelecem esses paradigmas em suas práticas pedagógicas no sentido de lidar com o tema saúde, no qual podemos perceber certa fragilidade nessa relação.

\section{Esporte e competição}

Atualmente, o esporte pode ser considerado o conteúdo mais frequente das aulas de Educação Física na escola, principalmente no que se refere ao Ensino Médio, no qual o que se observa é, em algumas vezes, o esporte desenvolvido como mera recreação e, em outras, como uma prática esportiva voltada unicamente ao rendimento. Parece-nos que o esporte, como um dos conteúdos da Educação Física, necessita de reflexão.

O esporte na escola tem sido objeto de muito estudo, numa clara tentativa de entender e compreender seu sentido e sua relação com os processos de formação educativa dos alunos. Há uma necessidade de justificar a presença do esporte no ambiente escolar e sua importância para a comunidade que dele se utiliza. Ideia que podemos perceber nas palavras de Molina NeTO:

[...] É importante que se relacione e se contextualize este esporte no âmbito da escola, enquanto instituição e campo de vivência social. É preciso lançar luz nesse palco, a fim de encontrar a razão e a necessidade dessa prática para o aluno, para a escola e para a sociedade [...] (1996, p.27).
Guedes (2004) sugere, como proposta da Educação Física escolar, que se assuma um novo quadro no contexto educacional, mudando suas estratégias e que não fiquem exclusivamente nas práticas esportivas e nas atividades físicas recreativas e sim que se trabalhe com conteúdos selecionados e organizados que possam contribuir para os alunos adotarem hábitos saudáveis levando a propiciar um estilo de vida no decorrer de suas vidas.

No sentido de dar outro enfoque para a Educação Física no Ensino Médio de forma a oferecer outras atividades além das costumeiras práticas esportivas, NAHAS (1997) propôs o desenvolvimento de conceitos e princípios sobre as questôes da saúde que possam proporcionar subsídios aos alunos no sentido de tomarem decisões quanto à adoção de hábitos saudáveis de atividades físicas ao longo da vida, podendo auxiliá-los na escolha de um estilo de vida ativo fisicamente. Segundo o autor, a Educação Física no Ensino Médio deve proporcionar ao aluno conhecimento sobre a cultura corporal de movimento, que implica compreensão, reflexão e análise crítica. A aquisição de tal corpo de conhecimentos deve ocorrer em relação às vivências das atividades corporais com objetivos vinculados ao lazer, saúde e bem estar.

Entendemos que debater o esporte por si só não é suficiente. Não temos como condenar sem antes analisar criticamente as atividades esportivas que se ensinam nas escolas. Temos de discutir o esporte escolar, incorreto, inadequado, reprovável, no que se refere ao processo educativo, considerando o quadro social em que tanto a escola quanto o esporte encontram-se inseridos. Assim, a escola não pode se distanciar dos fatos sociais que objetivam a formação dos alunos, e o esporte é um deles.

Para alguns autores, o esporte só faz sentido no ambiente escolar se passar por uma série de adaptações, o que resultaria em um esporte diferenciado, configurando-se no "esporte da escola". KunZ (2001) alerta para a necessidade de ocorrer uma "transformação didático-pedagógica do esporte", pois considera que, em todas as possibilidades de manifestação do esporte na sociedade, ele pode assumir um caráter educacional. Por isso, o autor entende que a escola é, por excelência, o lugar social específico em que a organização da situação educativa é formal, e acrescenta: [...] "O problema é descobrir 
que compromisso educacional a encenação pedagógica do esporte deve assumir quando da presença de um educador e no espaço escolar " [...] (p.73).

Kunz (2001), em seu trabalho sobre a transformação didático-pedagógica do esporte, questiona sob quais condições e de que forma o esporte deve e pode ser praticado na escola. $\mathrm{O}$ autor escreve que ao ensinar esporte na Educação Física deve-se trabalhar conteúdos de caráter teórico-prático, que permitam aos alunos perceberem melhor a sua realidade, de forma mais transparente, fazendo com que as suas diversas manifestações de movimentos e jogos aconteçam pelas suas necessidades e possibilidades e não simplesmente pela execução de habilidades e gestos técnicos das modalidades esportivas. $\mathrm{O}$ autor coloca que, dessa forma, o aluno pode interagir socialmente de forma coletiva, em que o objetivo educacional de ensinar e aprender se dá de forma responsável, cooperativa e participativa.

A visão reducionista do esporte nas aulas de Educação Física foi também evidenciada no tema
"Esporte e Competição", em que se destaca a seleção dos alunos habilidosos; a realização de torneios; os gestos técnicos e os fundamentos como principais meios de tratar o esporte, ressaltando as turmas de treinamento e a participação em competições, sempre apontando a aptidão como forma de seleção. Os professores reconhecem que esse é o melhor método de fazer com que os alunos se interessem pelo esporte no Ensino Médio e tiveram dificuldades em apontar uma visão dessa relação fora do âmbito competitivo e em abordar o esporte como uma possibilidade de conteúdo da Educação Física e suas outras formas de manifestação no ambiente escolar. Constatamos apenas que um professor apresentou uma grande preocupação em mudar essa visão, destacando que enfrenta enorme dificuldade, entre os professores, para conseguir alterar essa concepção. Fica evidente, então, por meio dessa pesquisa, que a concepção do esporte é sempre manifestada como um fim e não como um meio.

\begin{tabular}{|l|l|}
\hline UR - 04 & $\begin{array}{l}\text { a realidade do governo hoje e o esporte em si é trabalhado nas turmas de treinamento na época de } \\
\text { campeonatos. }\end{array}$ \\
\hline UR - 10 & $\begin{array}{l}\text { o nosso sistema educacional ele é baseado no sistema americano...é...onde lá o esporte funciona por } \\
\text { temporada tá...isso de uma maneira competitiva, a partir do segundo grau. }\end{array}$ \\
\hline UR - 13 & $\begin{array}{l}\text { condições pra gente começar si uma iniciação desportiva, criando-se futuros atletas para o país de uma } \\
\text { maneira organizada, sem especialização precoce. }\end{array}$ \\
\hline UR - 20 & $\begin{array}{l}\text { Então aqueles que tem aptidão eu canalizo pros treinamentos e...e a gente disputa aí nas diversas } \\
\text { modalidades é...com seriedade, trabalhando até mais que três horas semanais. }\end{array}$ \\
\hline UR - 24 & \begin{tabular}{l} 
Primeiro o fundamento para aprimorar o jogo em todas as aulas para que eles peguem gosto pelo esporte. \\
\hline UR - 25
\end{tabular} A gente faz o interclasse que é uma competição que dura todo o ano com as finais no finalzinho do ano. \\
\hline UR - 26 & \begin{tabular}{l} 
Retiro os alunos que têm aptidão para participar das competições externas. \\
\hline UR - 27
\end{tabular} Até porque esporte seria alto rendimento e poucas pessoas chegam nesse objetivo \\
\hline UR - 30 & $\begin{array}{l}\text { Quando trabalho esporte pelo esporte, eu procuro sempre relacionando ele...é além de estar } \\
\text { apresentando os aspectos técnicos de cada modalidade, a sua forma correta. }\end{array}$ \\
\hline UR - 34 & \begin{tabular}{l} 
Nas minhas aulas, só vale regra oficial, então eu não deixo regra caseira. \\
\hline UR - 39
\end{tabular} $\begin{array}{l}\text { O professor de educação física ele tira os alunos bons, o que ele considera bons e põe o resto pra fazer } \\
\text { qualquer coisa e ele já vai praticamente funcionar muito mais como treinador do que como alguém } \\
\text { que tenha uma visão mais ampla. }\end{array}$ \\
\hline
\end{tabular}

Atualmente a competição está inserida em todos os segmentos de nossa sociedade, o que, muitas vezes, é vista como um aspecto negativo. Assim, se lidarmos com a prática coerente do esporte, de forma a valorizar a competição, levará nossos jovens a aprenderem a lidar com seus limites e superaçôes.

Porém, o esporte pode ser considerado um reflexo de valores da sociedade, portanto, entendemos que deve haver uma preocupação do professor de Educação Física para que a exagerada competição, existente e muito presente no esporte-rendimento e no esporte-espetáculo, não esteja presente como principal objetivo da Educação Física escolar.

Outro aspecto importante a se considerar é que os meios de comunicação vêm dando enorme cobertura ao esporte de alta competição e isso provoca uma tendência de se constituir modelos para os praticantes em outros segmentos, principalmente, na escola. Essa supervalorização tem levado o esporte a ser enxergado apenas no aspecto competitivo, de 
concorrência, de seleção, e de rendimento o que tem norteado os profissionais de Educação Física em orientar suas práticas pedagógicas.

Kunz (2001) aponta que na concepção educacional da transformação didático-pedagógica do esporte, não se pretende eliminar o rendimento e a competição, mas demonstrar possibilidades de desenvolvê-los numa perspectiva do rendimento necessário, isto é, uma prática pedagógica capaz de superar as expectativas sociais, valorizando apenas o que o indivíduo produz ou é capaz de render, respeitando suas limitações.

Freire (1997, p.153) afirma que "ao invés de tentar eliminar o caráter competitivo dos jogos, os

\section{Esporte como aspecto cultural}

BЕTTI (1991) argumenta que o ensino do esporte deve servir a usos diversos, considerando tanto o aprendizado para a prática, como o aprendizado para o consumo crítico do fenômeno esportivo (p.55), e define como objetivo da Educação Física na escola, incluindo o esporte como um dos seus conteúdos:

[...] introduzir o aluno no universo cultural das atividades físicas, de modo a prepará-lo para delas usufruir durante toda sua vida [...]. Devem-se ensinar o basquetebol, o voleibol (a dança, a ginástica, o jogo...) visando não apenas o aluno presente, mas o cidadão futuro, que vai partilhar, produzir, reproduzir e transformar as formas culturais de atividade física. Por isso, na Educação Física escolar, o esporte não deve restringir-se a um "fazer" mecânico, visando um rendimento exterior ao indivíduo, mas tornarse um "compreender", um "incorporar", um "aprender" atitudes, habilidade e conhecimentos, que levem o aluno a dominar os valores e padrōes da cultura esportiva (p.58).

Para Kunz (2001), o esporte só atende ao compromisso de uma concepção crítico-emancipatória se passar por um processo de transformação didáticopedagógica e for desenvolvido a partir de uma didática comunicativa. Segundo o autor, isso se dá quando o aluno está "capacitado para participar da vida social, cultural e esportiva, o que significa não somente a aquisição de uma capacidade de ação funcional, mas a capacidade de conhecer, reconhecer e problematizar sentidos e significados através da reflexão crítica” (p.31).

A prática esportiva acontece para satisfazer as necessidades e as vontades humanas de tal maneira professores deveriam procurar compreendê-lo e utilizá-lo para valorizar as relações." O autor acredita "ser mais educativo reconhecer a importância do vencido e do vencedor do que nunca competir".

Assim concordamos com os autores e entendemos que o profissional de Educação Física, pela formação que possui, deve ser capaz de diferenciar o nível de competição que irá desenvolver com seus alunos, de forma diferenciada daquelas expostas pela mídia. No ambiente escolar, há a necessidade de que os alunos entendam a competição no esporte no seu sentido motivacional, em que a principal competição a ser incentivada é a do aluno consigo mesmo na busca de superação de seus próprios resultados.

que ela possa ser transformada, assumindo vários significados de acordo com seu contexto social e histórico, neste caso, para cumprir com os propósitos de uma educação emancipatória (KunZ, 2001).

Segundo Assis de Oliveira (2001): para que o esporte seja modificado, é necessário enxergá-lo como instituição social que produz e reproduz um sistema de valores, mas é imprescindível afirmar a sua condição de produção humana, como algo passível de transformação, inclusive pela prática pedagógica (p.197).

Quando determinada modalidade esportiva for abordada no ensino escolar, não se deve tratá-la apenas com suas regras, técnicas e táticas, mas também seu papel na sociedade, sua história, sobre assuntos referentes aos atletas, ou sobre temas polêmicos como a violência, o "doping", patrocinadores, em suma, extrapolar o rotineiro "jogar por jogar". O papel do professor é propiciar essa interação de realizaçôes, buscando a melhor compreensão do esporte em si, discutindo o que acontece no seu dia-a-dia, sem, é claro, transformar a aula em pura teoria.

Sobre o tema "Esporte visto como Aspecto Cultural", os professores enfatizam uma preocupação em estimular e incentivar as manifestaçôes esportivas regionalizadas, as quais são significantes culturalmente. Buscam valorizar cada vez mais esse tema como parte das aulas de Educação Física, identificando como fundamental no papel dessa disciplina na escola e na contribuição que o esporte promove à sociedade. Reconhecem que os esportes regionalizados servem de atrativos para serem abordados em suas aulas, devido à influência que recebem da própria sociedade, valorizando essa cultura. 


\begin{tabular}{|l|l|}
\hline UR - 14 & $\begin{array}{l}\text { respeitando os esportes regionalizados, respeitando a predominância esportiva de cada região, mas } \\
\text { dando condiçôes para que esse aluno possa aprender. }\end{array}$ \\
\hline UR - 22 & $\begin{array}{l}\text { Então é difícil você conseguir introduzir os outros esportes e eu consigo um pouco mais o handebol } \\
\text { feminino pela tradição da região. }\end{array}$ \\
\hline UR - 23 & Agora está entrando o basquete pela questão da cidade, também que vai virar uma questão cultural. \\
\hline UR - 36 & Aqui é grande a influência do basquete pela cidade ter um time de alto nível. \\
\hline
\end{tabular}

A Educação Física ao tratar da cultura de movimento deve buscar trabalhar essa sistematização, ou seja, organizar o conhecimento popular trazido pelos alunos e pela sua sociedade expressando a partir daí as suas mais variadas formas de manifestações que levarão o aluno a um conhecimento autônomo, crítico e organizado. Porém, somos cientes de que essa transformação não é o papel exclusivo dos professores de Educação Física, nem de suas formaçōes e outros requisitos, ela é um tanto quanto lenta, pois ainda esbarramos na tradição cultural de nossa própria sociedade que traz consigo a visão biológica de corpo, não se dando conta de que o homem é um ser biológico e cultural também. Não existe corpo sem cultura. Jogamos futebol, corremos, caminhamos, dançamos, jogamos basquetebol porque estamos inseridos em uma cultura que desenvolveu tais capacidades para nossos corpos (DAOLIO, 2003).
Assim, entendemos que a Educação Física deve se preocupar com sua prática no aspecto cultural, pois ao propor educar seus alunos por meio do corpo estará ela representando os valores e princípios da sociedade em que vivem. Concordamos com DAOLIO (2003) que afirma que um trabalho com competência se dará respeitando o acervo cultural dos alunos, o que revela a influência da sociedade, inclusive nas práticas das modalidades esportivas que trazem suas trajetórias, histórias e especificidades culturais de forma a situar a realidade para sua prática.

Nesse sentido nos cabe, enquanto professores de Educação Física, dar importância à ligação entre os interesses dos alunos e o elo cultural que os une, como a história, os hábitos, os costumes e as tradiçōes, marcando esses aspectos culturais inseridos em uma sociedade, possibilitando e viabilizando a estes mesmos alunos suas inserções como cidadãos.

\section{Esporte e modalidades tradicionais}

Conforme as sinalizações destacadas pelos Parâmetros Curriculares Nacionais do Ensino Médio (BRASIL, 2002), o esporte é tema e conteúdo relativo ao componente curricular Educação Física. A relação com a formação de um indivíduo fisicamente ativo e, não apenas como espectador, foi valorizada em termos de prescrição e orientação pedagógica.

A compreensão limitada do tema esporte tem levado muitos professores a confundirem os objetivos da instituição escolar com os objetivos da instituição esportiva, confundirem também o papel de educador com o de treinador, de aluno com atleta, de educação com treinamento. Portanto, faz-se necessário apresentar algumas referências nessa discussão, face aos possíveis desdobramentos que a instituição escolar pode produzir frente ao fenômeno esportivo. No que tange ao Ensino Médio, é fundamental que professores tenham uma percepção devidamente esclarecida sobre as relações entre Educação Física e o esporte, bem como junto aos outros temas da cultura corporal de movimento. Em função desses argumentos, é imprescindível a apresentação de uma parte das discussōes teóricas produzidas pela área, que não nos parece evidente e clara no corpo do discurso oficial.

Ao destacar o tema, "O Esporte na perspectiva das modalidades tradicionais", pudemos identificar a forte influência da formação tradicional, fato este evidenciado pelos relatos dos professores que destacam as modalidades esportivas aplicadas em seus gestos técnicos, táticas, fundamentos e regras. Isso demonstra que há um despreparo dos professores para atuarem no atual cenário em que o esporte deve ser tratado nas aulas de Educação Física. Esses aspectos podem servir de ferramentas fundamentais para incentivar a implantação de programas de capacitação, como formação continuada, proporcionando debates, discussões e reflexões. 


\begin{tabular}{|l|l|}
\hline UR - 01 & o que eu sempre trabalho, eu procuro ensinar basquetebol, voleibol, uma noção de handebol e futebol. \\
\hline UR - 06 & $\begin{array}{l}\text { então eu uso como base os desportos que eles estão acostumados entre aspas a tentar praticar que são: } \\
\text { futsal, vôlei, handebol e basquete. }\end{array}$ \\
\hline UR - 17 & $\begin{array}{l}\text { A educação física deve ser trabalhada os quatro esportes e o atletismo no mínimo pra que o aluno aprenda, } \\
\text { tenha a consciência que a prática esportiva é uma atividade física saudável e a pratique durante sua vida. }\end{array}$ \\
\hline UR - 29 & Os conteúdos que eu trabalho do esporte basicamente é...os fundamentos dos esportes. \\
\hline UR - 31 & $\begin{array}{l}\text { As modalidades que eu trabalho são as tradicionais porque justamente por causa do tempo, eu tam- } \\
\text { bém direcionando para área da saúde que eu gosto bastante. }\end{array}$ \\
\hline UR - 46 & $\begin{array}{l}\text { Então os esportes que eu estou fazendo é basquete né, que é dividido em quatro bimestres: basquete, } \\
\text { handebol, vôlei e futsal. }\end{array}$ \\
\hline
\end{tabular}

Numa análise mais aprofundada, observamos que não são só os professores formados há mais tempo que demonstram a visão tecnicista como método de abordagem em suas aulas de Educação Física na escola, há discursos pontuais que revelam claramente a relação da formação recebida com a prática aplicada, independente da época em que o professor se graduou. Isso nos leva ao reconhecimento de que o conhecimento científico gerado nas universidades renomadas na área não consegue provocar mudanças nas concepções sobre esporte desenvolvido nos cursos de graduação.

Podemos afirmar que os principais conteúdos das aulas de Educação Física no Ensino Médio são os esportes coletivos, considerados tradicionais (handebol, voleibol, basquetebol e futebol). Dentro das inúmeras modalidades dos esportes coletivos essas são as que mais se destacam, dentro da cultura brasileira (PAES, 1996).

Assim, como já foi dito, o ensino das modalidades esportivas coletivas vêm, ao longo dos anos, sendo reduzido de forma a reproduzir alguns padrões do esporte rendimento, ou seja, tem, em determinados momentos, privilegiado a repetição pura e simples de determinados gestos técnicos como garantia de sucesso na execução destes em situação de jogo.

Analisando aspectos já discutidos a respeito da história das influências sofridas por nossa área, observamos que os objetivos e propostas educacionais da Educação Física foram se modificando e todas essas tendências influenciaram a formação do profissional e as práticas pedagógicas dos professores (DARIDO, 1999).
No entanto, entendemos que essa situação não recai meramente sobre o professor como o principal responsável, mas também concordamos com DAOLIO (1995) quando aponta outros fatores que influenciam a prática profissional, como experiências vividas, salários, reconhecimento, entre outros e, principalmente, a estrutura de como são formados esses profissionais.

Outro aspecto importante são os meios de comunicação, a chamada mídia, que influenciam de maneira decisiva a Educação Física, informando e, muitas vezes ditando normas, construindo significados, modalidades e formas de consumo especialmente no esporte, pois os alunos vivenciam essa mídia de forma efetiva. Com isso, essa mesma mídia rivaliza com a escola e a família valores e atitudes, principalmente, na fase de formação desses alunos (BETTI, 2002).

Entendemos que a escola deve considerar o papel da mídia, pois ela está muito presente na vida dos alunos; porém, que isso seja feito de maneira crítica, reflexiva, criando um diálogo entre os mesmos para que assim possa se constituir um novo conceito de prática esportiva.

O valor educacional do esporte na escola deve estar em torno da transformação de conduta dos alunos, da formação de opinião e reestruturação de valores por intermédio das aulas de Educação Física (PAEs, 1996).

Assim cabe aos professores dessa disciplina trabalhar para modificar os ambientes tradicionais de ensino e caminhar coletivamente para transformar a visão culturalmente restrita e imediatista que se tem.

\section{Esporte e inclusão}

$\mathrm{Na}$ escola, é preciso retomar os valores que privilegiam o coletivo sobre o individual, buscando o compromisso da cooperação, da interação, do companheirismo e a compreensão de que o jogo se faz em conjunto, mostrando que o fazer jogar é uma ação com os companheiros e não com os adversários.

Ao oferecer o esporte na escola no sentido de romper com seus mitos, permitindo que seja criticado 
dentro de um contexto sócio-econômico-cultural, se faz necessário promover esse conhecimento, por meio da compreensão de significados de valores e normas que garantam o direito à prática do esporte. É importante salientar que o seu ensino não se esgota em gestos técnicos, pois se acredita que para dizer que o aluno possui "conhecimento" de determinados jogos que foram esportivizados não é suficiente que ele domine os seus gestos técnicos.
Foram identificadas manifestações explícitas de inclusão ao tratar o tema "Esporte e Inclusão", porém, não evidenciam formas de abordá-la. Os professores demonstraram um desconhecimento do que é inclusão e, principalmente, quando e como se dá na prática esportiva. Ao destacarem a questão da inclusão, abordam sobre forma de criar condiçôes para que seus alunos participem das aulas de Educação Física.

\begin{tabular}{|l|l|}
\hline UR - 02 & $\begin{array}{l}\text { então quando ele chega no colegial praticamente ele tem noção, ele não é um jogador, ele pratica um } \\
\text { esporte, então ele tem noção, pequena noção dos fundamentos para ele poder participar, porque a } \\
\text { educação física hoje na escola é voltada para a inclusão. }\end{array}$ \\
\hline UR - 03 & $\begin{array}{l}\text { você tem que fazer o aluno participar, tem que tá incluso, então se ele vai lá, um exemplo, vai jogar } \\
\text { vôlei, e ele dá um em vez de uma manchete um tapa na bola com as duas mãos, a bola vai pra cima, tá } \\
\text { valendo, ele tá participando. }\end{array}$ \\
\hline UR - 16 & $\begin{array}{l}\text { Então especialização precoce é uma coisa né...esporte dentro da escola é outra, e o pessoal confunde, } \\
\text { então a educaçáo física inclusiva não é inclusiva porcaria nenhuma. }\end{array}$ \\
\hline UR - 18 & $\begin{array}{l}\text { Principalmente do jeito que é hoje, que é dado misto, a aula é mista, então se você, já fiz experiência de pegar, } \\
\text { é colocar os meninos um dia na quadra jogando e tirar as meninas pra fazer atletismo que é o mais difícil. }\end{array}$ \\
\hline UR - 20 & $\begin{array}{l}\text { Então aqueles que tem aptidão eu canalizo pros treinamentos e...e a gente disputa aí nas diversas } \\
\text { modalidades é....com seriedade, trabalhando até mais que três horas semanais. }\end{array}$ \\
\hline
\end{tabular}

O fato é que essa inclusão por eles enfatizada se apresenta apenas na forma do discurso, pois fica claro, entre as estratégias utilizadas em suas aulas, que não há preocupações em buscar ou promover a inclusão dos alunos, pelo contrário, continua sendo da forma exclusiva e seletiva, separando até mesmo os alunos por sexo. Assim, o que se conclui é que eles têm consciência de que ela existe e deve ser aplicada, mas não relatam nenhuma ação em que ela apareça. Além disso, evidenciam sentimentos de insatisfação para lidar com esse tema, principalmente porque gera um maior esforço no planejamento das aulas, nas mudanças das propostas pedagógicas e as diferentes formas de didática, enfim, alteram a atuação desses profissionais. Muitos não reconhecem que esse é um problema de todos e que é necessário a participação deles na construção desse processo, que tem não só repercussões na área educacional, mas também em outros segmentos da sociedade. A Educação Física tem, em sua história, marcas que a mostram como exclusiva e seletiva, principalmente, no ambiente escolar.

Um dos princípios que norteiam os Parâmetros Curriculares Nacionais (BRASIL, 2002) para a área de Educação Física é o da inclusão, que tem como meta inserir todos os alunos na cultura corporal de movimento, por meio da reflexão e da participação concreta e afetiva.

O pressuposto básico é que o conceito de inclusão em Educação Física não se resume à inserção de alunos portadores de necessidades especiais na instituição escolar, refere-se, sim, a um contexto muito mais amplo, que engloba todas as pessoas que experimentam barreiras à aprendizagem e à participação.

A inclusão é um processo permanente de construção coletiva que parte da necessidade de enfrentar as barreiras da aprendizagem e buscar aumentar a participação de um ou mais alunos e, até mesmo, grupos que se encontram em condições de exclusão nas aulas de Educação Física.

DARIDO (2001) destaca que na história da Educação Física escolar sempre houve a seletividade a qual promove a exclusão. A autora entende que a intenção dos $\mathrm{PCN}$ s ao propor o princípio da inclusão foi de vislumbrar uma Educação Física escolar que supere a exclusão.

Assim, para construir formas de inclusão na Educação Física escolar é preciso que o professor reconheça os valores e as diversidades dos alunos e perceba que todos os alunos são capazes de aprender. Essa construção tem que se dar de forma coletiva e intencional que favoreça a participação e a aprendizagem de todos os alunos.

Para que isso realmente se concretize, não cabe ao professor de Educação Física reinventar o papel da educação, mas sim viabilizar condições que permitam experimentar e refletir na construção de práticas mais significativas aos alunos que realizam as ações pedagógicas. 
DARIDO (2001, p.21) afirma que "uma Educação Física integrada à proposta pedagógica da escola, com perspectivas educacionais realmente voltadas para a formação do cidadão precisa ter um olhar direcionado para a inclusão". A autora ainda enfatiza que "é preciso urgente uma Educação Física para todos, sem distinção de nenhuma ordem".

\title{
Considerações finais
}

O objetivo desta pesquisa foi o de apresentar a visão dos professores de Educação Física da rede pública e o conteúdo esporte em suas aulas no Ensino Médio. Assim, essa investigação nos permitiu conhecer como os professores percebem o esporte na escola, redefinindo conceitos e posturas, possibilitando a criação de propostas que viabilizem maior conhecimento do tema ampliando as formas de atuação desses profissionais no âmbito escolar.

Dessa forma, as entrevistas revelaram conhecimentos que refletem pouco a Educação Física e suas mudanças históricas e paradigmáticas, indicando certa dificuldade de compreendê-la no contexto escolar por seus próprios agentes, ou seja, os professores de Educação Física, sobretudo quando o esporte ainda aparece como o principal conteúdo e baseado em modelos esportivizados, tecnicistas visando à performance, ao rendimento, à aptidão física.

Outro fato aponta para uma carência de sistematização adequada de conhecimentos da Educação Física no Ensino Médio, o que consequentemente, nos leva ao entendimento de que as ações governamentais, atuais propostas e currículos não modificaram em quase nada as aulas de Educação Física no Ensino Médio, no caso, o conteúdo esporte, no qual as aulas permanecem com sequências pedagógicas dos esportes coletivos tradicionais, com execução de movimentos e gestos técnicos. Práticas como o planejamento participativo, o desenvolvimento da autonomia, a interdisciplinaridade parecem um tanto quanto distantes dessa realidade.

Certamente existem ainda muitas limitações, nem todos os problemas poderão ser resolvidos e muitos fatores independem das ações dos professores, mas devemos considerar a importância de uma articulação de ações conjuntas, no campo da formação profissional desses professores que atuam hoje nas escolas públicas, e enfrentam essas dificuldades, resistindo em aceitar as mudanças, em se adaptar às novas propostas pedagógicas.

Além disso, julgamos imprescindível a preparação dos professores para que sejam capazes de construir novos conhecimentos, aplicando-os, divulgando-os e criando estratégias de trabalho adequadas a todos os ambientes escolares. Levá-los a reconhecer o esporte como um dos conteúdos a serem trabalhados no Ensino Médio nas aulas de Educação Física. Refletir sobre a amplitude desse tema é de fundamental importância para a melhoria da formação profissional que hoje está no contexto escolar, se não ficaremos sempre presos às críticas, às desculpas e às justificativas, ao invés de buscarmos as soluções.

\begin{abstract}
The sport and the school: the vision of physical education teachers from public

This study investigated the view that the physical education teacher, who works in high school, has about the application of sport in their classes at school. We sought to identify which design attributed to sport and competition as well as verify the meaning of sports in this context. In a qualitative study, information was collected from a diagnostic form of schools, and a semistructured interview with these professionals. A general question guided the research: How do you see the relation Sports / Physical Education? The answers were interpreted using the technique of content analysis, BARDIN (2004). The study consists of two steps, first is a literature review on the issues that permeate sports in high school physical education and in the second, the methodological development of this research. These results suggest the sport due to the following themes: sport and education, declaring a lack of commitment by teachers, sports and health, which is configured with conceptual errors; sport and competition, which demonstrates a selective
\end{abstract}


emphasis on practice, sport as a cultural aspect, seen as vital in contributing to society's culture, sport in the perspective of traditional methods, defined as unique perspectives in pedagogical practice sport and inclusion that reveals the predominance of exclusive activities to more skilled.

UnITERMS: School physical education; Pedagogy of the sport; Medium teaching.

\section{Referências}

ASSIS DE OLIVEIRA, S. Reinventando o esporte: possibilidade da prática pedagógica. Campinas: Autores Associados, 2001. BARDIN, l. Análise de conteúdo. 3. ed. Lisboa: Ediçôes 70, 2004.

BETTI, M. Educação física e sociedade. São Paulo: Movimento, 1991.

Imagem e ação: a televisão e a educação física escolar (resultados iniciais). In: CONGRESSO BRASILEIRO DE CIÊNCIAS DO ESPORTE, 12., 2001, Caxambú. Anais.... Caxambú: CBCE, 2002.

BRASIL. PCN+ Ensino Médio: Orientaçôes Educacionais complementares aos Parâmetros Curriculares Nacionais. Linguagens, códigos e suas tecnologias/Secretaria de Educação Média e Tecnológica. Brasília: MEC/SEMTEC, 2002.

CORREIA, W.R. Planejamento participativo e o ensino da educação física no $2^{\circ}$ grau. Revista Paulista de Educação Física, São Paulo, v.10, p.43-8, 1996. Suplemento 2.

DAOLIO, J. Da cultura do corpo. Campinas: Papirus, 1995.

Cultura: educação física e futebol. Campinas: Editora da Unicamp, 2003.

DARIDO, S.C. Educação física na escola: questões e reflexões. Araras: Topázio, 1999.

DARIDO, S.C.; et al. A educação física, a formação do cidadão e os Parâmetros Curriculares Nacionais. Revista Paulista de Educação Física, São Paulo, v.15, n.1, p.17-32, 2001.

FREIRE, J.B. Educação de corpo inteiro: teoria e prática da educação física. São Paulo: Scipione, 1997.

FREITAS, L.C. Crítica da organização do trabalho pedagógico e da didática. Campinas: Papirus, 1995.

GUEDES, D.P. Fundamentos e princípios pedagógicos da educação física: uma perspectiva no campo da educação para a saúde. In: DARIDO, S.C.; MAITINO, E.M. (Orgs.). Pedagogia cidadã: cadernos de formação - educação física. São Paulo: UNESP, 2004. p.33-42.

KUNZ, E. A relação teoria/prática no ensino/pesquisa da educação física. Revista Motrivivência, São Cristovão, v.6, n.8, p.46-54, 1995.

- Transformação didático-pedagógica do esporte. 4. ed. Ijuí: Unijuí, 2001.

MÉRIDA, M. Caminhos de uma educação pública popular. 1995. Dissertação (Mestrado em Educação) - Universidade Mackenzie, São Paulo, 1995.

MOLINA NETO, V. A prática do esporte nas escolas de $\mathbf{1}^{\mathbf{0}}$ e $\mathbf{2}^{\mathbf{0}}$ graus. Porto Alegre: Editora Universidade/UFRGS, 1996. MOLINA NETO, V.; CORDERO, G. Um estudo interpretativo de uma atividade de formação permanente dirigida a professores de educação física de $2^{\circ}$ grau de Barcelona. Revista Brasileira de Ciências do Esporte, Campinas, v.18, n.1, p.16-26, 1996. NAHAS, M.V. Educação física no ensino médio: educação para um estilo de vida ativo no terceiro milênio. In: SEMINÁRIO DE EDUCAÇÃO FÍSICA ESCOLAR, 4., 1997, São Paulo. Anais... São Paulo: EEFEUSP, 1997. p.17-20 1997. PAES, R.R. Educação física escolar: o esporte como conteúdo pedagógico do ensino fundamental. 1996. Tese (Doutorado) - Faculdade de Educação Física. Universidade Estadual de Campinas, Campinas, 1996.

ENDEREÇO

Marco Aurélio Gonçalves Nóbrega dos Santos Av. Conceição, 531 18970-000 - Chavantes - SP - BRASIL e-mail: marcoaurelio67@hotmail.com
Recebido para publicação: 09/01/2008

1a. Revisão: 04/03/2010

2a. Revisão: 03/08/2010

3a. Revisão: 21/09/2010

Aceito: 04/ 10/2010 